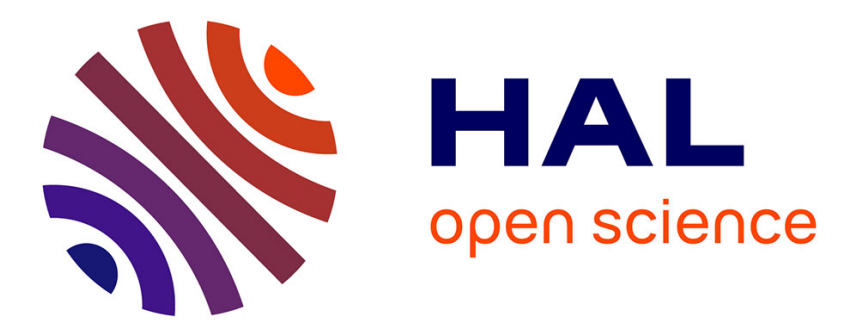

\title{
Functionalization of amorphous nitrogenated carbon thin film electrodes for improved detection of cadmium vs. copper cations
}

Serigne Massamba Seck, Stéphane Charvet, Modou Fall, Emmanuel Baudrin, Florence Geneste, Michaël Lejeune, Mohammed Benlahsen

\section{To cite this version:}

Serigne Massamba Seck, Stéphane Charvet, Modou Fall, Emmanuel Baudrin, Florence Geneste, et al.. Functionalization of amorphous nitrogenated carbon thin film electrodes for improved detection of cadmium vs. copper cations. Journal of electroanalytical chemistry and interfacial electrochemistry, 2015, 738, pp.154-161. 10.1016/j.jelechem.2014.11.013 . hal-01220893

HAL Id: hal-01220893

https://hal-univ-rennes1.archives-ouvertes.fr/hal-01220893

Submitted on 4 Nov 2015

HAL is a multi-disciplinary open access archive for the deposit and dissemination of scientific research documents, whether they are published or not. The documents may come from teaching and research institutions in France or abroad, or from public or private research centers.
L'archive ouverte pluridisciplinaire HAL, est destinée au dépôt et à la diffusion de documents scientifiques de niveau recherche, publiés ou non, émanant des établissements d'enseignement et de recherche français ou étrangers, des laboratoires publics ou privés. 


\title{
Functionalization of amorphous nitrogenated carbon thin film electrodes for improved detection of cadmium vs. copper cations.
}

\author{
Serigne Massamba SECK ${ }^{\mathrm{a}, \mathrm{b},{ }^{*}, \text { Stéphane CHARVET }}{ }^{\mathrm{a}}$, Modou FALL ${ }^{\mathrm{b}}$, Emmanuel \\ BAUDRIN $^{\mathrm{c}, \mathrm{d}}$, Florence GENESTE ${ }^{\mathrm{e}}$, Michaël LEJEUNE ${ }^{\mathrm{a}}$, Mohammed BENLAHSEN ${ }^{\mathrm{a}}$.
}

${ }^{\text {a }}$ Laboratoire de Physique de la Matière Condensée, UFR des Sciences d'Amiens, 33, rue Saint-Leu, 80028 Amiens Cedex, France.

${ }^{\mathrm{b}}$ Laboratoire de Chimie Physique Organique et d'Analyses Environnementales, Université Cheikh Anta Diop, BP 5005 Dakar-Fann, Sénégal.

${ }^{\mathrm{c}}$ Laboratoire de Glycochimie, des antimicrobiens et des agro-ressources CNRS FRE 3517, Université de Picardie Jules Verne. 1, rue des Louvels, 80037 Amiens, France.

${ }^{\mathrm{d}}$ Institut de Chimie de Picardie, FR3085 CNRS, Université de Picardie Jules Verne. 33, Rue Saint-Leu, 800039 Amiens Cedex, France.

${ }^{\text {e }}$ UMR 6226 «Institut des Sciences Chimiques de Rennes » Equipe Matière condensée et systèmes Electroactifs (MaCSE), Université de Rennes 1, Campus de Beaulieu, Bât 10C, 35042 Rennes Cédex.

*E-mail:seckas@gmail.com

\begin{abstract}
:
The specificity of a sensor relative to specific cations can be modified by functionalization of amorphous nitrogenated carbon thin film $\left(\mathrm{a}-\mathrm{C}: \mathrm{N}_{\mathrm{x}}\right)$ electrodes. This surface modification was performed through the reduction of diazonium salts presenting different functionalties which could interact selectively with ions in solution. Cyclic voltammetry from +0.3 to $-1.0 \mathrm{~V}$ vs. SCE was used for the grafting process leading to the formation of covalent $\mathrm{C}-\mathrm{C}$ bonds onto the film surface. The precursor concentration and number of cycles were optimized and correlated to the specificity and sensitivity for copper and/or cadmium ion detection. The coverage of the electrode was checked by cyclic voltammetry measurements using the $\mathrm{Fe}(\mathrm{CN})_{6}^{3-/ 4-}$ system, interface charge transfer and contact angle. It showed that the electroreduction of diazonium salt and grafting of substituted aryl groups was effective on the
\end{abstract}


surface of the a-C: $\mathrm{N}_{\mathrm{x}}$ electrodes. A greater sensitivity of the electrode to $\mathrm{Cd}^{2+}$ was observed for the highest concentrations of precursors (4-amino benzene carboxylic acid (4-ABA)) compared to the pristine electrodes. Moreover, a marked decrease of cadmium sensitivity is noted after grafting but at the same time with a decreased influence of copper on the $\mathrm{Cd}^{2+}$ signal, indicating a better specificity of these functionalized sensors.

Keywords: Copper ion, Cadmium ion, nitrogenated amorphous carbon, sputtering, electrografting, diazonium salt, anodic stripping, ion sensors, electroanalysis.

\section{Introduction}

Anodic stripping, based on the accumulation of trace elements on an electrode surface followed by re-oxidation, is among the most efficient electrochemical techniques to meet the demand for electroanalysis and remediation applied to water containing heavy metals $\left(\mathrm{Cd}^{2+}\right.$, $\mathrm{Pb}^{2+}, \mathrm{Hg}^{2+}, \mathrm{Zn}^{2+}, \mathrm{Cu}^{2+}, \mathrm{As}^{3+}, \mathrm{Co}^{2+}, \mathrm{Cr}^{2+}, \mathrm{Al}^{3+}, \mathrm{Ni}^{2+}$ and $\left.\mathrm{Bi}^{3+}\right)$. It is a very sensitive method and can allow the detection of concentrations down to $10^{-12} \mathrm{M}$ [1]. To achieve this, several types of materials have been used as transducers for the development of accurate and reliable chemical sensors. The most commonly used materials are boron-doped diamond (BDD) [2-4], gold [5-7], and more recently bismuth [8-10] or nanostructured carbon thin films [11-14] electrodes. We previously showed that amorphous nitrogenated carbon thin films were also a good alternative for the detection of heavy metals in aqueous solution. a-CNx electrodes have a wider potential window than BDD electrode, with namely a good stability between $-1.3 \mathrm{~V}$ vs. SCE and $+1.6 \mathrm{~V}$ vs. SCE. The residual current is low enough to perform trace analysis [15].

Besides, the selectivity and the specificity are usually the major challenges for the development of sensors because of the multiple potential interferences during the measurement process. Some authors have studied these interferences by electrochemical costripping models [16], while others took an interest in avoiding them by using specific electrolytes [17]. However, the surface modifications by electrochemical and/or thermal routes are nowadays mostly used to solve this problem. For that purpose, electrografting onto the electrode of a specifically designed chemical functionality for the recognition of a heavy metal is an elegant approach [18-20]. Usually, surface functionalization consists in covering 
the surface with an organic or biological molecule which specifically interacts with the substances to detect, namely biological substances, ionic or molecular species. Numerous functional macromolecules, either organic or biological molecules [23,24], were used to induce interfacial recognition [21,22] on carbon substrates [25], semiconductors [26] or metals [25].

An attractive method that is now widely used to immobilize organic layers on electrodes is the electrochemical reduction of aryl diazonium salts. As first demonstrated by Delamar et al. in 1992 [27], it leads to the covalent modification of electrodes such as carbon surfaces. Two main techniques can be used to synthesize the diazonium salts: reaction of $\mathrm{NOBF}_{4}$ with an amine in an organic medium [28,29] or their in situ generation [30-34] in an aqueous acidic solution at low temperature via the reaction of sodium nitrite $\left(\mathrm{NaNO}_{2}\right)$ with an amino group (Fig. 1).

Various conventional methods (Raman or FTIR spectroscopy [29, 35-37], XPS [37-40], TOFSIMS [41], EQCM [42] and AFM [37,43]) have allowed to demonstrate the formation of strong covalent bonds of organic molecules on various substrates. Furthermore, the presence of this layer [37] can also easily be demonstrated by both cyclic voltammetry experiments performed before and after grafting using a fast redox couple such as ferri/ferrocyanide and by contact angle determination [26].

We previously noticed that the detection of $\mathrm{Cd}^{2+}$ in the presence of $\mathrm{Cu}^{2+}$ was significantly improved (better sensitivity and linearity) for a-CNx thin films compared to BDD electrodes [15]. In this work, we report on further improvement of the selectivity of these electrodes towards cadmium ions by modifying their surface with aryl based functionalities. The functionalization of these amorphous nitrogenated carbon thin films prepared by RF magnetron sputtering was achieved by electroreduction of aryl diazonium salts. The resulting modified electrodes were then tested for the detection of $\mathrm{Cd}^{2+}$ in the presence of $\mathrm{Cu}^{2+}$.

\section{Experimental}

\subsection{Materials and reagents}

All the reagents were of analytical grade. Copper acetate and cadmium acetate were purchased from Sigma-Aldrich. All functionalized aniline compounds (4-amino benzene carboxylic acid (4-ABA), 4-aminothiophenol (4-ATP) and p-phenylenediamine (PPD)), acetic acid, potassium chloride, hydrochloric acid and sodium acetate were purchased from ALFA 
AESAR. The electrolyte solutions were obtained by dissolving the reagents in aqueous acetate buffer. Acetate buffer was chosen for two reasons: using the same anion as for the used heavy metals salts and limiting any signal modification due to $\mathrm{pH}$ variation [15].

The substrates for thin films deposition were titanium disks (Goodfellow, polished and etched, 99.6+\% purity, thickness $0.7 \mathrm{~mm}$ and diameter $10 \mathrm{~mm})$. The electrochemical reactivity was assessed using a three-electrode cell arrangement with a saturated calomel electrode (SCE) and a large area platinum mesh as reference and counter electrodes, respectively. The a-CNx thin films deposited on polished titanium disk were used as working electrode. The backside of the conductive substrate, onto which the thin film was deposited, was stuck onto a copper ribbon using colloidal silver paste, the ribbon was itself stuck on a glass microscopy slice. The copper ribbon and the substrate were then covered by a resin (Araldite 2011, Hunstman, Switzerland) to allow only the carbon film to be in contact with the test solutions thus avoiding parasitic reactions.

\subsection{Procedures}

a-CNx thin films were synthesized using the radio-frequency (13.56 MHz) magnetron sputtering technique. Namely, a graphite target was bombarded with accelerated ions in nitrogen/argon plasma. The extracted atoms were then condensed on the substrate surface. This latter was previously ultrasonically cleaned in acetone, ethanol and distilled water, followed by an in situ sputtered argon etching to remove residual contaminants. The amount of nitrogen incorporated into the film can be controlled by the composition of the plasma (nitrogen/argon ratio) used during the deposition. The thickness of the deposited films, determined using a DEKTAK III profilometer, was maintained constant in the present work at a value of about $200 \mathrm{~nm}$. We previously showed that the electrochemical reactivity tested with ferri-ferrocyanide system and the electrical conductivity was optimal for an atomic nitrogen percentage of $13 \%$ in the film [15]. These conditions were fixed here for the formation of the a-CNx working electrodes.

The modification of a-CNx thin films by electrofunctionalization was electrochemically performed by the reductive electrolysis of diazonium salts on the electrode surface. Diazonium salts were directly generated in the electrochemical cell by the spontaneous diazotization method using an aromatic amine presenting an adequate substituent in the para position relative to the amino group $\left(-\mathrm{NH}_{2}\right)$. The in situ transformation of the amine into a diazonium salt $\left(-\mathrm{N}_{2}{ }^{+}\right)$was carried out with an aqueous sodium nitrite solution $\left(\mathrm{NaNO}_{2} 1.05\right.$ equiv/mol of amine) in acidic medium $(\mathrm{HCl}, \mathrm{pH}=2)$ at low temperature $\left(\mathrm{T}=0^{\circ} \mathrm{C}\right)$. For this 
process, a low temperature is necessary to avoid the decomposition of the diazonium salt. After the reduction of the diazonium salt onto the electrode surface, an ultrasonic treatment in bi-distilled water was performed for 5 minutes to remove all adsorbed substances that had not reacted.

To optimize the electroanalytical properties of a-CNx electrode, we used three different diazonium salts (differing in the substitution functionality in the para position of the amine). In the present work, we chose carboxylic acid $(-\mathrm{COOH})$, thiol $(-\mathrm{HS})$ and amino $\left(-\mathrm{NH}_{2}\right)$ functionalities. Fig. 2 shows the different chemical configurations of these diazonium cations.

The electrochemical grafting was carried out under stirring (400 rpm) in a cyclic voltammetry mode ( 5 cycles) between 0 and $-1.5 \mathrm{~V}$ vs. SCE at $100 \mathrm{mV} \mathrm{s}^{-1}$. The aqueous electrolyte was composed of $5.25 \mathrm{mM} \mathrm{NaNO}_{2}, 0.5 \mathrm{M} \mathrm{HCl}$ and $5 \mathrm{mM}$ 4ABA, 4ATP or PPD.

A three-electrode configuration was used in a $50 \mathrm{~mL}$ electrochemical cell. All solutions were degassed using nitrogen bubbling. A PalmSens potentiostat-galvanostat system interfaced with PStrace was used for the determination of the analytical properties. To activate the electrodes, a preliminary electrochemical treatment was systematically performed. It consisted in cycling the electrode between $-1.9 \mathrm{~V}$ and $0.0 \mathrm{~V}$ vs. SCE for 5 to $10 \mathrm{mins}$ in acidic medium $\left(\mathrm{H}_{2} \mathrm{SO}_{4} 0.5 \mathrm{M}\right)$. We previously showed that the latter treatment favors the electron transfer rate on unmodified a-CNx thin films [15]. Cyclic voltammetry was used for the grafting process and the electrochemical investigations of a-CNx electrodes reactivity. Differential Pulse Anodic Stripping Voltammetry (DPASV) was applied for the detection of metallic ion traces. For each experiment, a preliminary potentiostatic treatment was performed at $+0.5 \mathrm{~V}$ vs. SCE to remove any adsorbed/deposited species on the working electrode surface. The accumulation/pre-concentration was achieved by applying a deposition potential of -1.1 V vs. SCE for $120 \mathrm{~s}$ under stirring (400 rpm). After this step, the magnetic stirring was stopped, and the system left for $15 \mathrm{~s}$. Re-dissolution scans were set from -1.1 to $+0.3 \mathrm{~V} / \mathrm{SCE}$ with a scan rate of $50 \mathrm{mV} \mathrm{s}^{-1}$. The other analytical parameters are: a potential step fixed to $10 \mathrm{mV}$, a 30 $\mathrm{mV}$ potential pulse with a $50 \mathrm{~ms}$ pulse duration. For all these experiments a measurement was systematically performed on a blank solution. This latter was subtracted from the curves obtained in the presence of the cation(s) and led to the calibrating curve. From the plot of the peaks current density vs. concentration, we determined the slope which gives the sensitivity $\left(\mathrm{S}_{\mathrm{x}}\right)$ with their linear concentration range as indicated in the tables. 


\section{Results and discussion}

\subsection{Aryl groups electrografting on a-CNx electrode surfaces}

The cyclic voltammograms obtained by reduction of diazonium salts on the a-CNx surface electrodes are shown in Fig. 3. The grafting process is associated with the cathodic wave that appears to be completed at about $-0.8 \mathrm{~V}$. We chose to extend the potential to a more cathodic potential. Indeed, applying moderate electrolysis overpotential with regard to the standard potential of the ionic species may, in a pure kinetic point of view, result in a significant increase of the quantity of electrografted material on the electrode surface. The increasing current appearing from $-1.3 \mathrm{~V}$ vs. SCE is assigned to the evolution of hydrogen and has no effect on grafting mechanism. As previously reported [44], in these conditions the nitrites species could be reduced concomitantly with the diazonium salts. However this should not affect the electrografting process. Moreover, the current densities after the first cycle are lowered (in absolute values) because lower amounts of diazonium salts are electrografted (lower electron transfer due to the coverage of the surface during the first cycle). The process was limited to five scans.

The first cycle presents the characteristic signal of irreversible aryl groups electrografting during the reduction of 4ABA (Fig. 3.I), 4ATP (Fig. 3. II) and PPD (Fig. 3. III) diazonium salts on the a-CNx surface electrode. As expected, the reduction peak potentials are different for the different salts. The obtained values are $-0.2,-0.4$ and $-0.6 \mathrm{~V}$ vs. SCE for the PPD, 4ABA, and 4-ATP, respectively (Fig. 3). Table 1 shows the peaks potentials and currents obtained during the first reduction of the corresponding diazonium salts formed in situ, and their Hammet constant for a para position relative to the diazonium functionality $[45,46]$.

The latter parameter, characteristic of the chemical nature and position of the substituent functionality, may be correlated with different properties, among which the redox potential. Here, the reduction peak potential (Ep) is function of the Hammett constant $\left(\sigma_{p}\right)$ of the corresponding substituent in the para position (Fig. 4). This constant is linked to the activation energy and characterizes the electron-donating or withdrawing effect of the substituent in para position and gives indication on the evolution of the molecule reactivity. Several studies on the reduction of diazonium salts have previously directly correlated reduction peak potential to the Hammett coefficients $\left(\sigma_{\mathrm{p}}\right)[47,48]$. In fact, as the aryldiazonium salt benzene ring is depleted in electrons (for example by the electron- 
withdrawing group $-\mathrm{N}_{2}^{+}$), the reduction of the diazonium salt is facilitated and so the reduction potential is more positive. Conversely, with donating groups (or less withdrawing groups, as the para $\mathrm{SH}$ group for instance), the reduction of the diazonium cation is more difficult.

In the case of PPD, we could expect a bis-diazotation, however the obtained linear correlation supports the idea of a single diazotation with a protonated amino group $\left(\mathrm{NH}_{3}^{+}, \sigma_{\mathrm{p}}=0.66\right)$ (Fig. 4) and confirms that the second amine group of the "mono-diazotized" phenylenamine is less reactive and therefore no further reaction can be observed [49]. Finally, from the second cycle, voltammograms show a "passivation" of the a-CNx electrode with a significant decrease of the residual current and a complete disappearance of the reduction peak (Fig. 3). In fact, this passivation is due to a blocking of the reaction process by the aryl groups layers formed on the surface of the a-CNx electrode.

\subsection{Evolution of the wettability:}

The surface energy of a solid depends on the type of groups present on its surface. Thus electrofunctionalization of the amorphous nitrogenated carbon layer is expected to have an impact on the charge transfer behavior at the electrode/electrolyte interface. We first characterized the wettability of the electrolyte on the a-CNx modified electrode. Fig. 5 shows the pictures of droplets of distilled water before and after grafting thiophenol groups.

The 4-thiophenol acid and 4-benzene carboxylic acid induce an increase of the contact angle from $32(\sigma=1.03)$ to $79^{\circ}(\sigma=2.16)$ and from $30(\sigma=1.33)$ to $47^{\circ}(\sigma=0.89)$, respectively. This indicates that the hydrophobicity increases in the presence of the aromatic ring. This effect is more pronounced for the thiophenol group grafting. In addition, for the PPD, the contact angle increases $\left(80^{\circ}\right.$ after grafting) but is not uniform over the whole extent of the layer.

\subsection{Charge transfer behavior of the functionalized films}

Another way to check the electrode surface modification is to evaluate the evolution of the electrochemical properties of the thin films. Fig. 6 shows the voltammograms of a-CNx electrode obtained in a $10^{-3} \mathrm{M}$ potassium ferricyanide/ $0.5 \mathrm{M} \mathrm{KCl}$ solution before and after the 
surface modification through the reduction of 4-ABA (Fig. 6.I), 4-ATP (Fig. 6.II) and PPD diazonium salts (Fig. 6.III).

We can clearly see a sharp decrease or even the disappearance of ferri/ferrocyanide peaks after the electrochemical treatment. This can be explained either by the saturation of the a$\mathrm{CNx}$ surface by aryl groups or more likely by the formation of a barrier which prevents the electroactive couple from accessing the surface. For similar grafting conditions, the surface modification by 4-thiophenol aryl groups leads to a more compact layer covering the entire surface of the a-CNx electrode and completely blocking charge transfer between the electroactive species in the electrolyte system and the active sites of the electrode surface either through an electrostatic or a "mechanical" interaction.

However for the a-CNx electrode modified by 4-ATP and 4-ABA, electrostatic interactions cannot account for such a barrier as the surface will be either neutral or negative whereas the electroactive species are positive. Indeed, the pKa of carboxylic acid (COOH) (4.2) is consistent with a deprotonation of the acidic group, giving $\left(\mathrm{COO}^{-}\right)$[50] in the used conditions. From an electrochemical study, it has been shown that grafted groups have identical pKa values than in homogeneous aqueous solutions [51]. Similarly, the $\mathrm{pKa}=6.6$ of the aminothiophenol should lead to about an equimolar amount of protonated (-SH) and unprotonated $\left(-\mathrm{S}^{-}\right)$surface species [52]. The presence of a compact layer thus more likely explains these results.

\subsection{Grafting effect on the electroanalytical performances: $\mathrm{Cd}^{2+}$ and/or $\mathrm{Cu}^{2+}$ detection.}

In our previous works, we reported on the electrochemical properties of unmodified a-CNx thin films applied to the detection of $\mathrm{Cd}^{2+}$ and $\mathrm{Cu}^{2+}$ ions [15]. Thus, we want here to clarify the effect of electrode modification, namely through surface grafting using different diazonium salts (4-benzene carboxylic acid, 4-thiophenol and $p$-phenylamine) as described above.

\subsubsection{Effect of grafting aryl functionalities on $\mathrm{Cd}^{2+}$ or $\mathrm{Cu}^{2+}$ single detection}

From the electrochemical curves obtained in the DPASV mode, we can clearly observe that the functionalization obviously changes the response. Fig. 7 shows for example the stripping scans for copper (Figs. 7.I and 7.II) and cadmium (Figs. 7.III and 7.IV) detection before (Fig. 7.I and Fig. 7.III) and after (Fig. 7.II and 7.IV) electrofunctionalization from PPD diazonium salt in $0.1 \mathrm{M}$ acetate buffer $(\mathrm{pH}=4.9)$. We can note a significant drop of the current densities 
after surface modification, which is due to the passivation of the electrode surface after grafting, leading to a lowering of its reactivity. This phenomenon has already been underlined above for the ferri/ferrocyanide redox couple (section 3.3), the oxidation signal of $\mathrm{Fe}\left[(\mathrm{CN})_{6}\right]^{4-}$ into $\mathrm{Fe}\left[(\mathrm{CN})_{6}\right]^{3-}$ decreasing drastically (Fig. 6).

The electroanalytical parameters obtained from these electrochemical measurements, for pristine and modified a-CNx films, are reported in Table $2\left(\mathrm{Cd}^{2+}\right)$ and Table $3\left(\mathrm{Cu}^{2+}\right)$. We can see that the recorded sensitivities obtained from the slopes of the peak current vs. ion concentration straight lines (Fig. 7) are greatly lowered and depend on the type of functionalization, while still keeping a usable linear analytical domain. Indeed, for instance, the sensitivity for cadmium ( $\mathrm{Sx}=0.054 \mu \mathrm{A} \mathrm{cm} \mathrm{ppb}^{-1}$ ) of a-CNx electrode modified by a phenylamine group is ten times higher than the one obtained for a-CNx film modified with a thiophenol $\left(\mathrm{Sx}=0.005 \mu \mathrm{A} \mathrm{cm} \mathrm{ppb}^{-1}\right)$. On the other hand, the functionalization with a benzoic acid group leads to a complete "passivation" and cadmium is no longer detected in this case. Similar observations can be made for the detection of copper using films functionalized using with acidic or amino functionalities.

The passivation effect was expected due to the multilayer electrografting process, but an improvement of the selectivity is still observed with the sensor: the signal of cadmium is visible with the PPD whereas those of copper disappeared. This decrease of the sensitivity towards copper when the electrodes are functionalized can result from different processes. It would mean that the charge transfer at the thin film interface does not take place due to electrostatic and/or specific interactions (Lewis acid/base interactions). For instance, intermediate $\mathrm{Cu}^{2+}$ Lewis acid according to Pearson's classification interacts rather with amine bases than soft thiophenol base. Thus the related current and sensitivities are more depleted with PPD (Table 3). Similarly, cadmium ion (soft acid) will interact more with thiophenol functionality than for the PPD. Using the three simple functionalities described above, we thus underline here that there is a possibility to better control the interface through Lewis base grafting.

\subsubsection{Grafting effect on simultaneous detection of $\mathrm{Cu}^{2+}$ and $\mathrm{Cd}^{2+}$ :}


We have established in the previous paragraph that electrografting of $p$-phenylamine groups provide a sensitivity that is still rather high for cadmium $\left(\mathrm{Sx}=0.054 \mu \mathrm{A} \mathrm{cm} \mathrm{ppb}^{-1}\right)$ as compared to the important sensitivity decrease observed for copper (absence of related peak for this latter). These a-CNx modified electrodes thus provide relative selective responses to cadmium ion compared to copper ion. The next step was to evaluate the responses when the two cations were present within the same solution. As usually reported for stripping measurements, the presence of multiple ions modifies the peak intensities related to these ions as compared to the detection into solutions containing a single cation to detect. In the present case, $\mathrm{Cd}^{2+}$ which has the more cathodic standard potential, tends to be deposited onto the metal which presents a higher potential and which is deposited first (namely copper) as it was largely reported [15, 53-55]. Various phenomena may take place, including the formation of defined compounds or solid solutions in the $\mathrm{Cd}-\mathrm{Cu}$ system, etc., as detailed in length in our previous works [15].

For these experiments, we chose to evaluate the PPD modified a-CNx thin films (Fig. 8). The solutions were prepared by successive dilutions from the most concentrated one, thus keeping constant the concentration ratios $\left[\mathrm{Cd}^{2+}\right] /\left[\mathrm{Cu}^{2+}\right]$.

The sensitivities of the pristine films for the detection of cadmium and copper are $\mathrm{S}_{\mathrm{x}} \mathrm{Cd}^{2+}=$ $0.04 \mu \mathrm{A} \mathrm{cm}^{-2} \mathrm{ppb}^{-1}$ and $\mathrm{S}_{\mathrm{x}} \mathrm{Cu}^{2+}=0.18 \mu \mathrm{A} \mathrm{cm}^{-2} \mathrm{ppb}^{-1}$, respectively. In a previous paper, we already discussed such measurement, with notably an influence of the presence of copper on the cadmium peak [15]. We see here that the sensitivity is higher for copper than for cadmium. However, when functionalized with PPD, the a-CNx electrode response is more selective for cadmium $\left(\mathrm{S}_{\mathrm{x}} \mathrm{Cd}^{2+}=0.007 \mu \mathrm{A} \mathrm{cm}{ }^{-2} \mathrm{ppb}^{-1}\right)$ compared to copper $\left(\mathrm{S}_{\mathrm{x}} \mathrm{Cu}^{2+}\right.$ close to zero). Eyen though the signal is unfortunately very noisy, the results of $\mathrm{Cd}^{2+}$ peaks are clearly identifiable and usable for electroanalysis (Fig. 8.B).

Although a positive impact of the electrode modification by electrografting of a-CNx thin films is shown here, a thorough study of the electrofunctionalization of a-CNx electrode is required. For this purpose, we tested the effect of the electrografting parameters (notably concentrations of precursors) to improve the DPASV curve resolution.

\subsubsection{Influence of precursors concentrations:}

We have seen above that the detection signals of cadmium and copper were totally lost when the electrode was modified through an electrografting process using $5 \mathrm{mM}$ of the $p$ - 
aminobenzoic acid. We chose to modify the concentration of the starting precursor, keeping all the other parameters (for both grafting and detection processes) unchanged. The voltammograms obtained for the detection of cadmium (2 ppb) with a-CNx electrode modified by reduction of $p$-aminobenzoic acid diazonium salts at concentrations of 5,1 and $0.25 \mathrm{mM}$ are shown in Fig. 9. We noticed that the electrochemical sensitivity of cadmium increased when the concentration of $p$-aminobenzoic acid decreased (Fig. 9) underlining a better electron transfer and a better access of the metallic cations on the electroactive a-CNx surface. Thus, by controlling the concentration of the precursor, it is possible to modify the electrode by $p$-benzoic acid groups, keeping a high sensitivity to cadmium.

The electrochemical response of cadmium was then studied in the presence of copper ions at different concentrations, using the electrode modified by electrochemical reduction in a 0.25 $\mathrm{mM}$ solution of $p$-aminobenzoic acid diazonium salt. Table 4 summarizes the results for detection of cadmium as a function of copper concentration with a-CNx electrode modified by p-benzoic acid $(0.25 \mathrm{mM})$. First, although there is a non-visible copper signal, it interferes with that of cadmium.

Also, the linear ranges increased when the $p$-benzoic acid group is grafted, according to the $\mathrm{Cu}^{2+}$ concentration. As shown on Table 4, the cadmium linear range is narrower and starts at higher cadmium concentrations when the copper concentration is higher. We can see that with $139 \mathrm{ppb}$ of $\mathrm{Cu}^{2+}$, the cadmium ion concentration can be detected within a linearity range of only 1.26-12.6 ppb with the non-functionalized a-CNx electrode. After surface functionalization with $\mathrm{ABA}$ in optimal conditions, the linearity range becomes 25.1 - 99.6. The range of detectable concentrations is therefore in a higher concentrations domain.

As outlined by the decrease of the Sx values when copper concentrations increase, even if the signal of copper is not visible, it interferes with those of cadmium. However, compared with the Sx values obtained with an unmodified electrode, the cadmium sensitivity is less affected by the increase of copper concentrations on the a-CNx modified electrode. This is clearly underlined by the ratio $\mathrm{R}_{\mathrm{x}}=\mathrm{Sx}_{\mathrm{after}} / \mathrm{Sx}_{\text {before }}$, where $\mathrm{Sx}_{\mathrm{after}}$ and $\mathrm{Sx}_{\text {before }}$ are the sensitivities of the a-CNx modified electrode towards metallic cations $\left(\mathrm{Cd}^{2+}\right)$ before and after electrografting, respectively. Indeed, despite a decrease in the sensitivity of the modified electrode in the 
presence of copper, the $\mathrm{R}_{\mathrm{x}}$ ratio increases, showing the ability of a-CNx modified electrode to detect cadmium with high concentrations of copper in solution.

Fig. 10 illustrates the interest of the $p$-benzoic acid modified a-CNx electrode for the detection of cadmium in the presence of copper (copper concentration fixed to $14 \mathrm{ppb}$ ). Compared with a pristine electrode (Fig. 8), only a well-defined cadmium signal is observed.

These curves open a lot of perspectives if we can play on the grafting of different Lewis bases to bottom-up build new selective and sensitive sensors for heavy metals.

\section{Conclusions}

We have studied here the effect of functionalization of a-CNx thin films on cadmium and copper detection with the expectation to reduce interference of copper on the detection of cadmium. A surface modification was obtained by electrofunctionalization through diazonium salt reduction. First, we showed that the functionalization led to a decrease of the electrochemical reactivity of the modified electrode a-CNx with namely decreased sensitivities. For some cases, this decrease goes towards a complete blocked surface (physical barrier). However, we have observed that varying the type of functionality and in optimal preparation conditions; it is possible to still have a sensitive response towards cadmium ions while decreasing the copper signal. The next step will be to screen new Lewis bases to adjust and optimize the a-CNx electrode surface to build on demand electrodes for the specific detection of heavy metal traces for environmental applications. 
References:

[1] J. Wang, Analytical Electrochemistry, second edition, Wiley-VCH, New York, 2000.

[2] O. El Tall, N. Jaffrezic-Renault, M. Sigaud, O. Vittori, Electroanalysis 19 (2007) 1152-1159.

[3] D. Dragoe, N. Spătaru, R. Kawasaki, A. Manivannan, T. Spătaru, D.A. Tryk, A. Fujishima, , Electrochim. Acta 51 (2006) 2437-2431.

[4] M. Langeloth, M. Chiku, Y. Einaga, Electrochim. Acta 55 (2010) 2824-2828.

[5] J. Gong, T. Zhou, D. Song, L. Zhang, Sens. Actuators B, 150 (2010) 491-497.

[6] C.S. Oh, H. Kim, S. Rengaraj, Y. Kim, Microporous Mesoporous Mater. 147 (2012) 1-4.

[7] S. Laschi, I. Palchetti, M. Mascini, Sens. Actuators B, 44 (2006) 460-465.

[8] G. Kefala, A. Economou, A. Voulgaropoulos, M. Sofoniou, Talanta 61 (2003) 603-610.

[9] J. Wang, Electroanalysis 17 (2005) 1341-1346.

[10] Ma. De la Gala Morales, Ma R. Palomo Marín, L. Calvo Blázquez, E. Pinilla Gil, Electroanalysis 24 (2012) 1170-1177.

[11] Y.Q. Gu, J.G. Huang, Nanostructured Functional Inorganic Materials Templated by Natural Substances, in: J. Li (Ed), Nanostructured Biomaterials, Springer Berlin Heidelberg, 2010, pp. 31-82.

[12] C. Qiu, X. Dong, H. Ma, S. Hou, J. Yang, Electroanalysis 24 (2012) 1201-1206.

[13] G. Martínez-Paredes, M.B. González-García, A. Costa-García, Electrochim. Acta 54 (2009) 4801-4808.

[14] O.M. Küttel, O. Gröning, Ch. Emmenegger, L. Nilsson, E. Maillard, L. Diederich and L. Schlapbach, Carbon 37 (1999) 745-752.

[15] S.M. Seck, S. Charvet, M. Fall, E. Baudrin, M. Lejeune and M. Benlahsen, Electroanalysis 24 (2012) 1839-1846.

[16] G.Zhao, X. Tong, Z. Hu, X. Xiao and D. Li, Electrochim. Acta 53 (2008) 4283-4292.

[17] C. Babyak and R.B. Smart, Electroanalysis 16 (2004) 175-182.

[18] R. Nasraoui, D. Floner, F. Geneste, Electrochem. Commun. 12 (2010) 98-100.

[19] R. Nasraoui, D. Floner, F. Geneste, J. Electroanal. Chem. 629 (2009) 30-34.

[20] R. Nasraoui, D. Floner, C. Paul-Roth, F. Geneste, J. Electroanal. Chem.638 (2010) 9-14.

[21] P.A. Lieberzeit and F.L. Dickert, Anal. Bioanal. Chem. 387 (2007) 237-247.

[22] P. Namour, M. Lepot and N. Jaffrezic-Renault, Sensors 10 (2010) 7947-7978.

[23] J.J. Gooding, Electroanalysis 14 (2002) 1149-1156.

[24] B.P. Corgier, C.A. Marquette and L.J. Blum, J. Am. Chem. Soc. 127 (2005) 18328-18332.

[25] J.J. Gooding, Electroanalysis 20 (2008) 573-582.

[26] J. Pinson and D. Bélanger, Chem. Soc. Rev. 40 (2011) 3995-4048.

[27] M. Delamar, R. Hitmi, J. Pinson, , J-M. Saveant, J. Am. Chem. Soc.114 (1992) 5883-5884.

[28] F. Le Floch, J-P. Simonato and G.Bidan, Electrochim. Acta 54 (2009) 3078-3085. 
[29] P. Allongue, M. Delamar, B. Desbat, O. Fagebaume, R. Hitmi, J. Pinson, J-M. Saveant, , J. Am.Chem. Soc. 119 (1997) 201-207.

[30] T. Breton, D. Belanger, Langmuir, 24 (2008) 8711-8718.

[31] M. Pandurangappa, N.S. Lawrence, R.G. Compton, Analyst 127 (2002) 1568-1571.

[32] M. Pandurangappa, T. Ramakrishnappa and R.G. Compton, Carbon 47 (2009) 2186-2193.

[33] G. Chamoulaud, D. Belanger, J Phys Chem. C 111 (2007) 7501-7507.

[34] M. Toupin, D. Belanger D., J Phys Chem. C 111 (2007) 5394-5401.

[35] Y.C. Liu, R.L. McCreery, Anal. Chem. 69 (1997) 2091-2097.

[36] P. Allongue, C.H. De Villeneuve, G. Cherouvrier, R. Cortès and M.C. Bernard, J. Electroanal. Chem. 550-551 (2003) 161-174.

[37] M.P. Stewart, F. Maya, D.V. Kosynkin, S.M. Dirk, J.J. Stapleton, C.L. McGuiness, D.L. Allara, J.M. Tour, J. Am. Chem. Soc. 126 (2004) 370-378.

[38] A. Adenier, M.C. Bernard, M.M. Chehimi, E. Cabet-Deliry, B. Desbat, O. Fagebaume, J. Pinson and F. Podvorica, J. Am. Chem. Soc. 123 (2001) 4541-4549.

[39] C.H. de Villeneuve, J. Pinson, M.C. Bernard, P. Allongue, J. Phys. Chem. B 101 (1997) 24152420.

[40] K. Boukerma, M.M. Chehimi, J. Pinson, C. Blomfield, Langmuir 19 (2003) 6333-6335.

[41] C. Combellas, F. Kanoufi, J. Pinson, F.L. Podvorica, Langmuir 21 (2005) 280-286.

[42] A. Laforgue, T. Addou and D. Bélanger, Langmuir 21 (2005) 6855-6865.

[43] F. Anariba, S.H. DuVall and R.L. MeCreery, Anal. Chem. 75 (2003) 3837-3844.

[44] J. Agullo, M. Morin, D. Belanger, EDS Transactions (2011) 35(36) 16-26.

[45] C. Hansch, A. Leo, R.W. Taft, Chem. Rev. 91 (1991) 165-195.

[46] L.P. Hammett, J. Am. Chem. Soc. 59 (1937) 96-103.

[47] S. Baranton, D. Belanger, J. Phys. Chem. B 109 (2005) 24401-24410.

[48] R.M. Elofson, F.F. Gadallah, J. Org. Chem. 34(4) (1969) 854-857.

[49] J. Lyskawa and D. Bélanger, Chem. Mater. 18 (2006) 4755-4763.

[50] M.G. Paulik, P.A. Brooksby, A.D. Abell and A.J. Downard, J. Phys. Chem. C 111 (2007) 78087815.

[51] C. Saby, B. Ortiz, G.Y. Champagne and D. Bélanger, Langmuir 13 (1997) 6805-6813.

[52] J-P. Danehy, C.J. Noel, J. Am. Chem. Soc. 82 (1960) 2511-2515.

[53] A. Manivannan, R. Kawasaki, D. A. Tryk, A. Fujishima, Electrochim. Acta 49 (2004) 3313-3318.

[54] C. Prado, S. J. Wilkins, F. Marken, R. G. Compton, Electroanalysis 14 (2002) 262-272.

[55] W. R. MacKinnon, "Insertion electrodes I: Atomic and electronic structure of the hosts and their insertion compounds", in Solid State Electrochemistry (Ed: P. G. Bruce), Cambridge University Press, Cambridge 1995. 


\section{Table 1}

Characteristics of the first reduction peak as a function of the diazonium salt nature obtained by cyclic voltammetry with an a-CNx electrode at a $100 \mathrm{mV} \mathrm{s}^{-1}$ scan rate.

\begin{tabular}{cccc}
\hline Diazonium salts & $\mathrm{E}_{\mathrm{p}}(\mathrm{V}$ vs. SCE) & Constant $\sigma_{\mathrm{p}}[44]$ & $\left|\mathrm{I}_{\mathrm{p}}\right| \mu \mathrm{A} \mathrm{cm} \mathbf{c m}^{-2}$ \\
\hline PPD & -0.2 & $1.91^{*}\left({\left.\mathrm{~N} \equiv \mathrm{N}^{+}\right)}\right.$ & 59.6 \\
4-ABA & -0.4 & $0.66\left(\mathrm{NH}_{2}\right)$ & 33.4 \\
4-ATP & -0.6 & 0.45 & 37.1 \\
\hline
\end{tabular}




\section{Table 2}

Characteristic analytical parameters obtained before and after organic functions grafting (operating conditions: $5 \mathrm{mM}$ diazonium salts, 5 cycles and $100 \mathrm{mV} \mathrm{s}^{-1}$ ) on a-CNx electrode surfaces for a single ion detection (cadmium) in acetate buffer $0.1 \mathrm{M} ; \mathrm{pH}=4.9$. The electroanalysis conditions were $\mathrm{E}_{\mathrm{dep}}=$ $-1.1 \mathrm{~V} ; \mathrm{T}_{\mathrm{dep}}=120 \mathrm{~s} ; \mathrm{V}_{\mathrm{b}}=50 \mathrm{mV} \mathrm{s}^{-1}$.

\begin{tabular}{|c|c|c|c|}
\hline \multirow{2}{*}{$\begin{array}{c}\text { Diazonium salts } \\
5 \mathrm{mM} \text { and } 5 \text { cycles }\end{array}$} & \multirow{2}{*}[\mathrm{Cd}^{2+}]{$(\mathbf{p p b})$} & \multicolumn{2}{|c|}{$S_{x}\left(\mu A c^{-2} p p^{-1}\right)$} \\
\hline & & Before & After \\
\hline 4-aminobenzoic acid (4-ABA) & 2 to 11.5 & 0.449 & No peak \\
\hline p-phenylenediamine (PPD) & 2 to 7.5 & 0.449 & 0.054 \\
\hline 4-aminothiophenol (4-ATP) & 2 to 11.5 & 0.449 & 0.005 \\
\hline
\end{tabular}


Table 3

Characteristic analytical parameters obtained before and after organic functions grafting (conditions used $5 \mathrm{mM}$ diazonium salts, 5 cycles and $100 \mathrm{mV} \mathrm{s}^{-1}$ ) on a-CNx electrode surfaces for a single ion detection of copper in acetate buffer $0.1 \mathrm{M} ; \mathrm{pH}=4.9$. The electroanalysis conditions were $\mathrm{E}_{\mathrm{dep}}=-1.1$ $\mathrm{V} ; \mathrm{T}_{\mathrm{dep}}=120 \mathrm{~s} ; \mathrm{V}_{\mathrm{b}}=50 \mathrm{mV} \mathrm{s}^{-1}$.

\begin{tabular}{cccc}
\hline Diazonium salts & {$\left[\mathbf{C u}^{\mathbf{2}}\right]$ (ppb) } & \multicolumn{2}{c}{$\mathbf{S}_{\mathbf{x}}\left(\boldsymbol{\mu} \mathbf{A} \mathbf{~ c m}^{-2} \mathbf{p p b}^{\mathbf{1}}\right)$} \\
\cline { 3 - 4 } $\mathbf{5}$ mM and 5 cycles & & Before & After \\
\hline 4-aminobenzoic acid (4-ABA) & 7 to 35 & 0.316 & No peak \\
p-phenylenediamine (PPD) & 7 to 35 & 0.316 & No peak \\
4-aminothiophenol (4-ATP) & 7 to 35 & 0.316 & 0.007 \\
\hline
\end{tabular}




\section{Table 4}

Simultaneous cadmium detection as a function of copper concentration in acetate buffer $0.1 \mathrm{M}$; $\mathrm{pH}=$ 4.5; $\mathrm{E}_{\text {dep }}=-1.1 \mathrm{~V} ; \mathrm{T}_{\mathrm{dep}}=120 \mathrm{~s} ; \mathrm{V}_{\mathrm{b}}=50 \mathrm{mV} \mathrm{s}^{-1}$. The electroanalytical parameters were obtained with a$\mathrm{CNx}$ before and after grafting $p$-benzoic acid $\left(0.25 \mathrm{mM}, 1\right.$ cycle and $\left.100 \mathrm{mV} \mathrm{s}^{-1}\right)$.

\begin{tabular}{|c|c|c|c|c|}
\hline \multirow[t]{2}{*}[\mathrm{Cu}^{2+}]{$(\mathrm{ppb})$} & \multicolumn{2}{|c|}{$\left[\mathrm{Cd}^{2+}\right]$ linearity range $(\mathrm{ppb})$} & \multirow{2}{*}{$\begin{array}{c}\mathrm{S}_{\mathrm{X} \text { after }} \\
\left(\mu \mathrm{A} \mathrm{cm} \mathrm{cmb}^{-2} \mathrm{ppb}^{-1}\right)\end{array}$} & \multirow[t]{2}{*}{$\mathrm{R}_{\mathrm{x}}=\mathrm{S}_{\mathrm{x} \text { after }} / \mathrm{S}_{\mathrm{x} \text { before }} *$} \\
\hline & Before & After & & \\
\hline 139 & 1.26 to 12.6 & 25.1 to 99.6 & 0.003 & 0.155 \\
\hline 14 & 1.26 to 12.6 & 6.3 to 99.6 & 0.005 & 0.145 \\
\hline 0 & 1.26 to 12.6 & 1.26 to 99.6 & 0.006 & 0.075 \\
\hline
\end{tabular}

${ }^{*} \mathrm{R}_{\mathrm{x}}=1$ would mean that the a-CNx modified electrode is specific for $\mathrm{Cd}^{2+}$ because before and after grafting sensitivities are equal and independent to $\mathrm{Cu}^{2+}$ contents. $\mathrm{R}_{\mathrm{x}} \neq 1$ denotes a variation of $\mathrm{Cd}^{2+}$ sensitivity with $\mathrm{Cu}^{2+}$ content. It can be defined as a return of specificity or sensitivity of a-CNx modified electrode to $\mathrm{Cd}^{2+}$ compared to $\mathrm{Cu}^{2+}$ cation. 
Images :

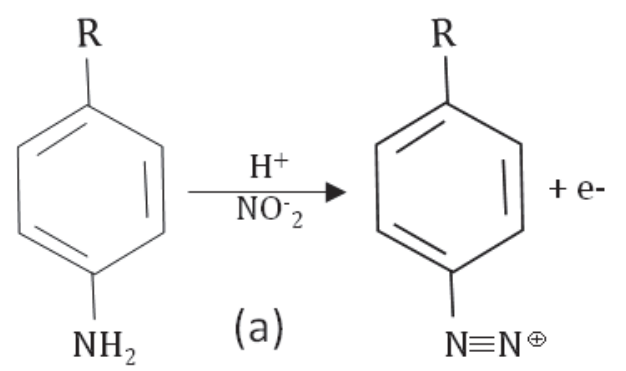

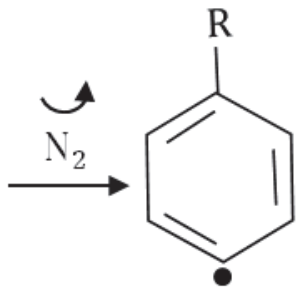

(b)

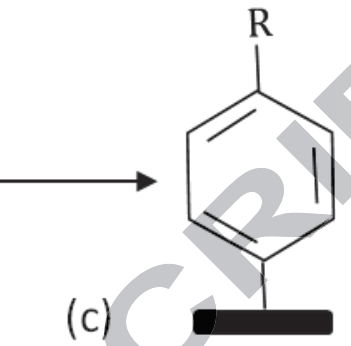

(c)

Figure 1 : Grafting process through the electrochemical reduction of diazonium salts. (a) Spontaneous diazotization; (b) Electrochemical reduction and (c) Grafting on the electrode surface. 

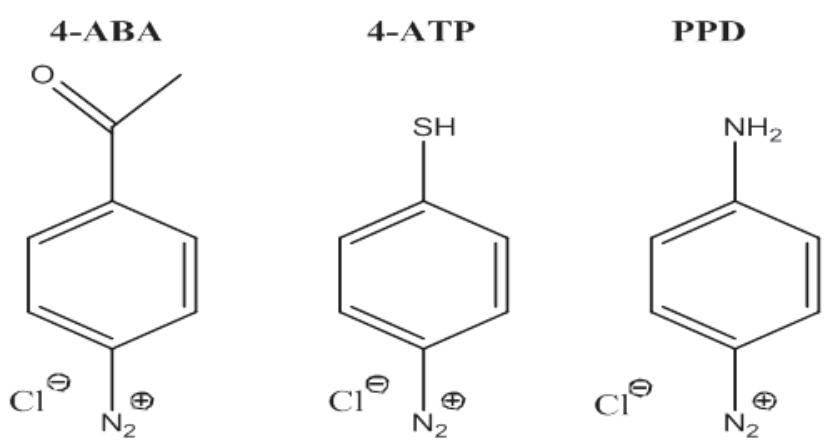

Figure 2 : Chemical configurations of the diazonium salts formed in situ to functionalize the a-CNx films. 

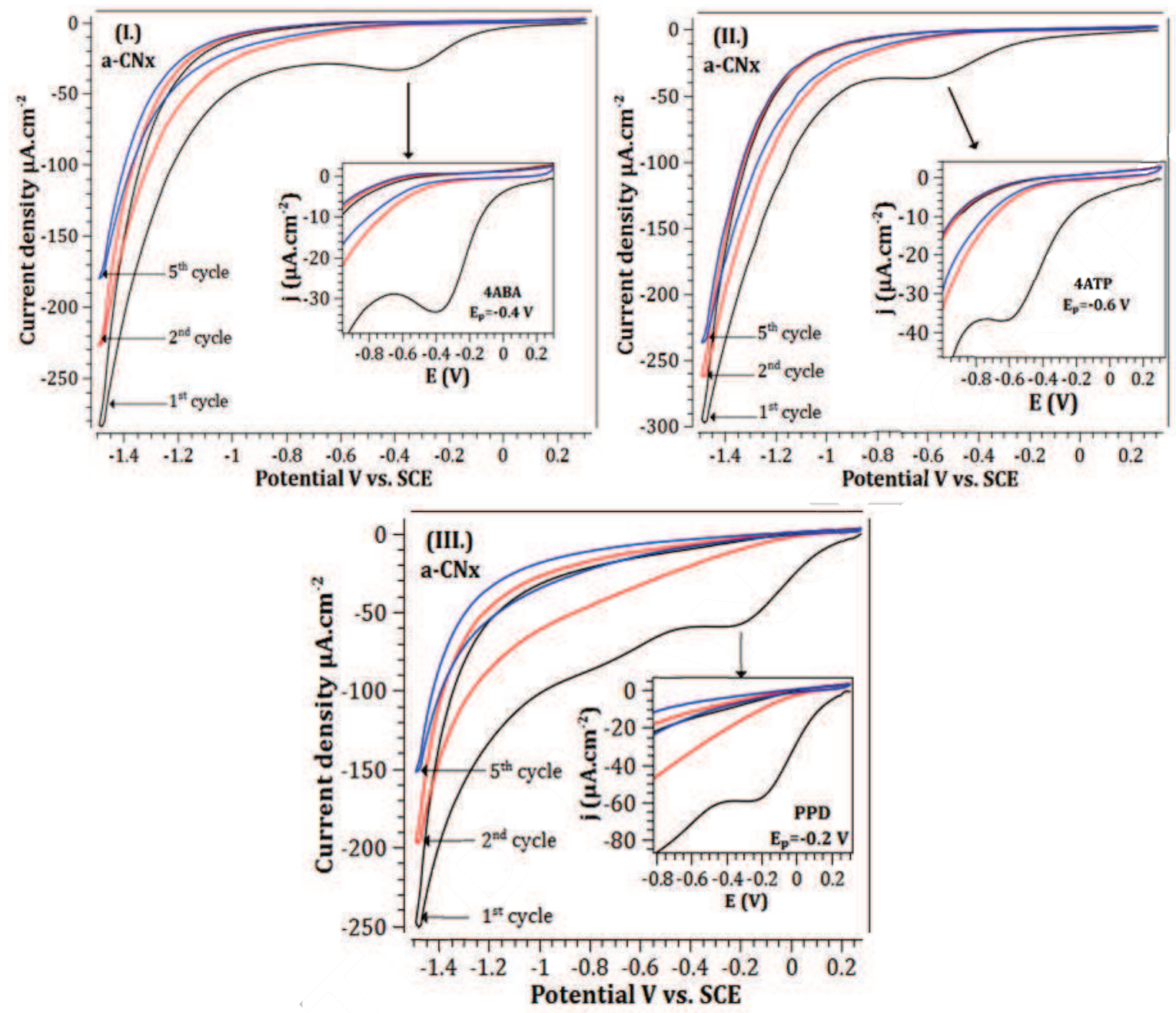

Figure 3: Cyclic Voltammograms of an a-CNx electrode in a solution of $\mathrm{HCl} 0.5 \mathrm{M}+5 \mathrm{mM}$ of I). 4aminobenzene carboxylic acid (4ABA); (II.) 4-aminothiophenol (4ATP); (III.) p-phenylenediamine (PPD); + 5.25 $\mathrm{M} \mathrm{NaNO}_{2} .(\mathrm{pH}=2)$; Scan rate: $100 \mathrm{mV} \mathrm{s}^{-1}$. 


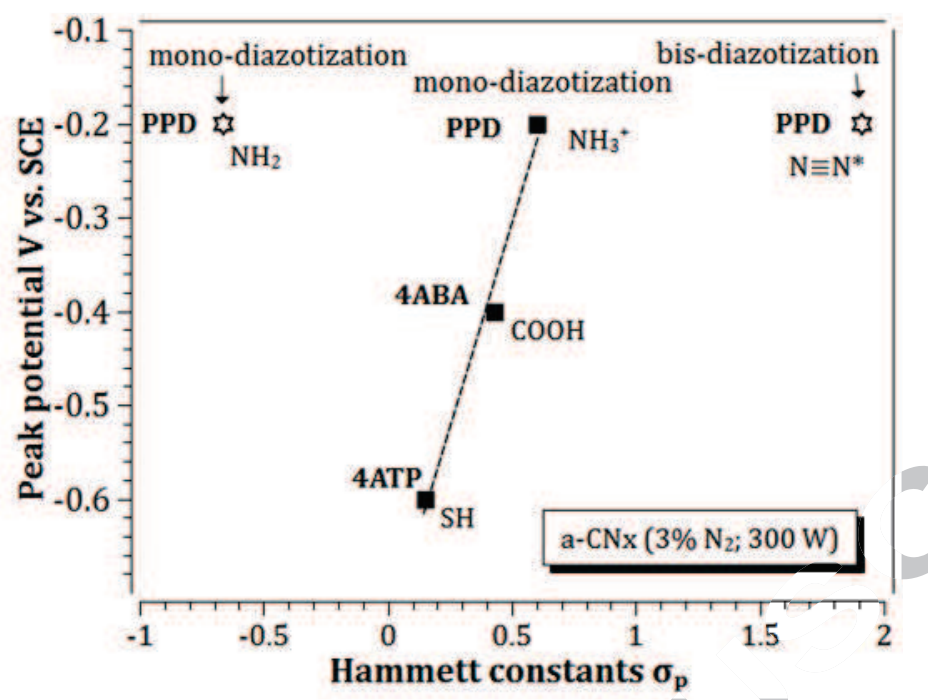

Figure 4 : Correlation between reduction peak potential of diazonium salts $(5 \mathrm{mM}$ in $\mathrm{HCl} 0.5 \mathrm{M})$ and Hammett sigma para constants. Scan rate: $100 \mathrm{mV} \mathrm{s}^{-1}$. 


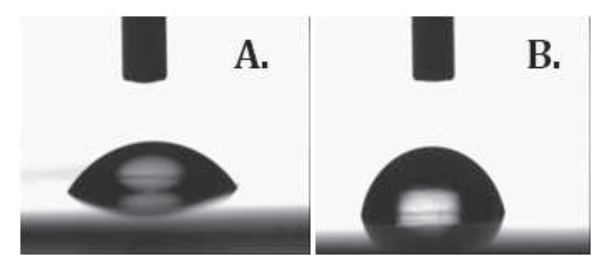

Figure 5: Images of distilled water droplets on a-CNx electrode surface A.) before and B.) after functionalization with thiophenol groups in $5 \mathrm{mM} \mathrm{NaNO}_{2} \cdot\left(5\right.$ cycles at a scan rate of $\left.100 \mathrm{mV} \mathrm{s}^{-1}\right)$ 

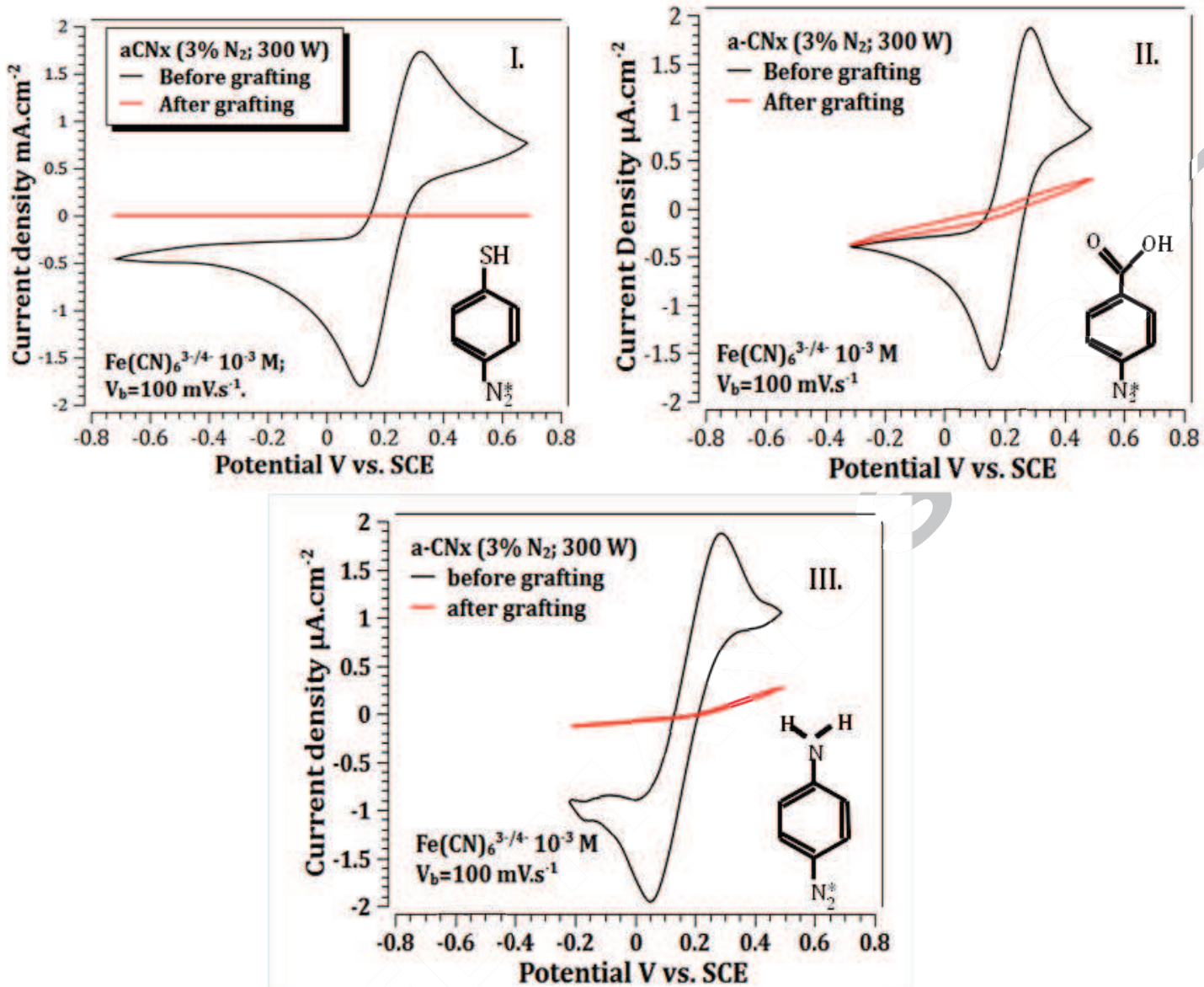

Figure 6 : Electrochemical response of a-CNx electrode in $\mathrm{K}_{3} \mathrm{Fe}\left(\mathrm{CN}_{6}\right) 10^{-3} \mathrm{M}$ in $\mathrm{KCl} 0.5 \mathrm{M}$ before and after 5 reductive cycles in $\mathrm{NaNO}_{2} 5.25 \mathrm{mM}+\mathrm{HCl} 0.5 \mathrm{M}$ and $5 \mathrm{mM}$ (I). 4ABA, (II). 4ATP and (III) $\mathrm{PPD}, \mathrm{pH}=6.5 ; \mathrm{V}_{\mathrm{b}}=100 \mathrm{mV} \mathrm{s}^{-1}$. 

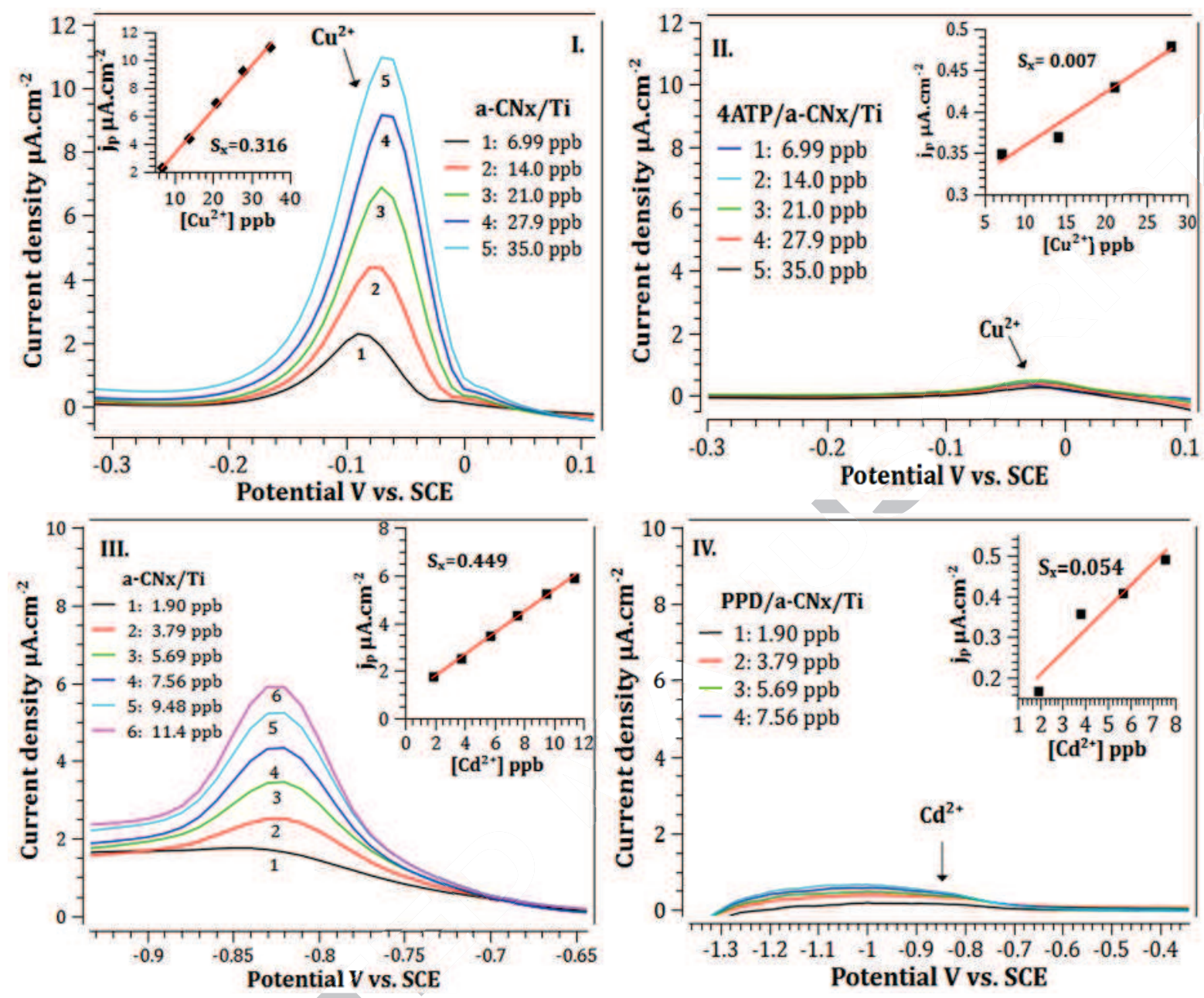

Figure 7: Anodic stripping voltammograms of a-CNx electrodes before (I. and III.) and after modification (II. and IV.) for the detection of $\mathrm{Cu}^{2+}$ (I. and II.) and $\mathrm{Cd}^{2+}$ (III. and IV.) in acetate buffer $0.1 \mathrm{M}(\mathrm{pH}=4.90) ; \mathrm{E}_{\text {step }}=10 \mathrm{mV} ; \mathrm{E}_{\text {pulse }}=30 \mathrm{mV} ; \mathrm{E}_{\text {dep }}=-1.1 \mathrm{~V} ; \mathrm{T}_{\mathrm{dep}}=120 \mathrm{~s} ; \mathrm{V}_{\mathrm{b}}=50 \mathrm{mV} . \mathrm{s}^{-1}$. In insert, we reported the peak current density as a function of cation concentration. 

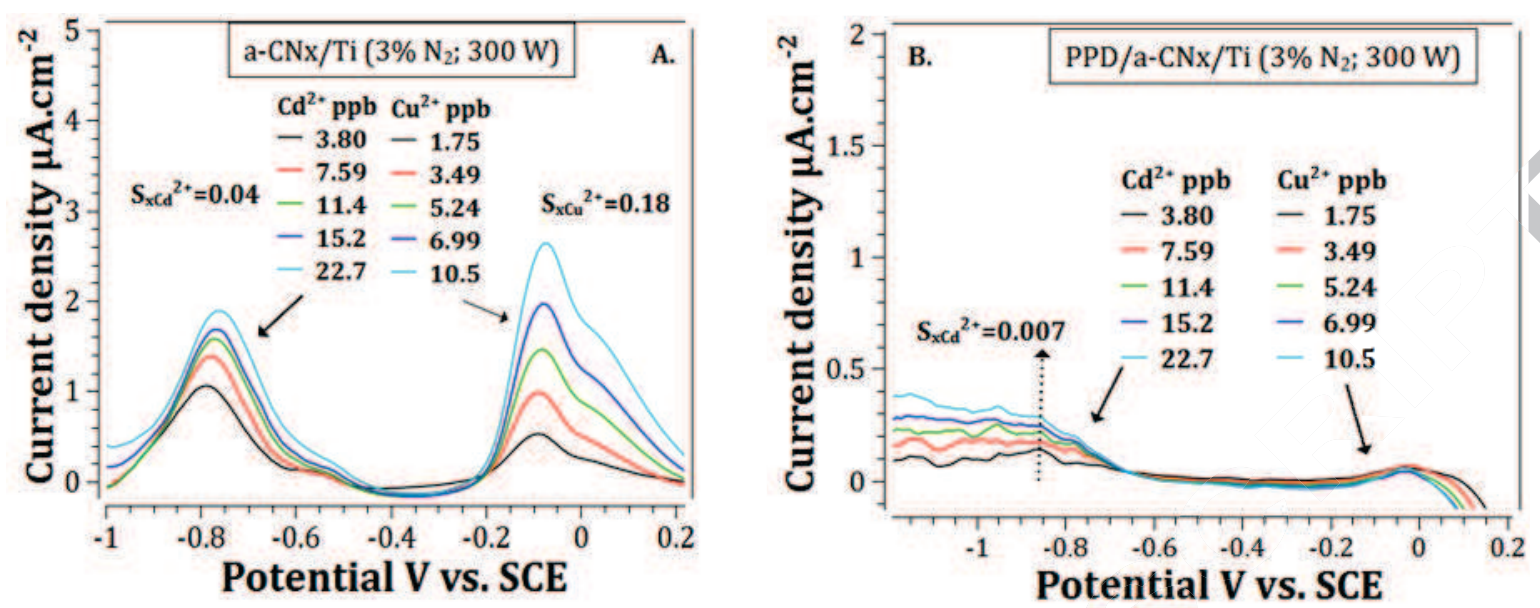

Figure 8: DPASV Voltammograms of an a-CNx electrode A) before and B). after electrografting of pphenylenediamine from $5 \mathrm{mM}$ corresponding diazomium salt in acetate buffer $0.1 \mathrm{M} ; \mathrm{pH}=4.9 ; \mathrm{E}_{\text {step }}=$ $10 \mathrm{mV} ; \mathrm{E}_{\text {pulse }}=30 \mathrm{mV} ; \mathrm{E}_{\mathrm{dep}}=-1.1 \mathrm{~V} ; \mathrm{T}_{\mathrm{dep}}=120 \mathrm{~s} ; \mathrm{V}_{\mathrm{b}}=50 \mathrm{mV} \mathrm{s}^{-1}$. 


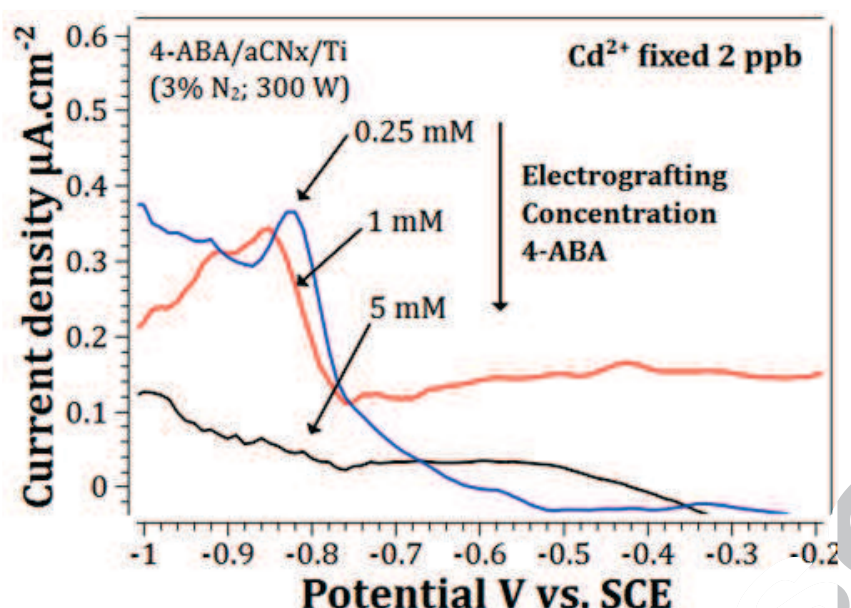

Figure 9: Electrochemical response in a DPASV mode for a benzoic acid modified a-CNx electrode using different diazonium salt concentrations $(5 ; 1$ and $0.25 \mathrm{mM} ; 1$ cycle). Acetate buffer $0.1 \mathrm{M}$ and $\mathrm{Cd}^{2+} 2 \mathrm{ppb} ; \mathrm{pH}=4.9 ; \mathrm{E}_{\text {step }}=10 \mathrm{mV} ; \mathrm{E}_{\text {pulse }}=30 \mathrm{mV} ; \mathrm{E}_{\text {dep }}=-1.1 \mathrm{~V} ; \mathrm{T}_{\text {dep }}=120 \mathrm{~s} ; \mathrm{V}_{\mathrm{b}}=50 \mathrm{mV} \mathrm{s}^{-1}$. 


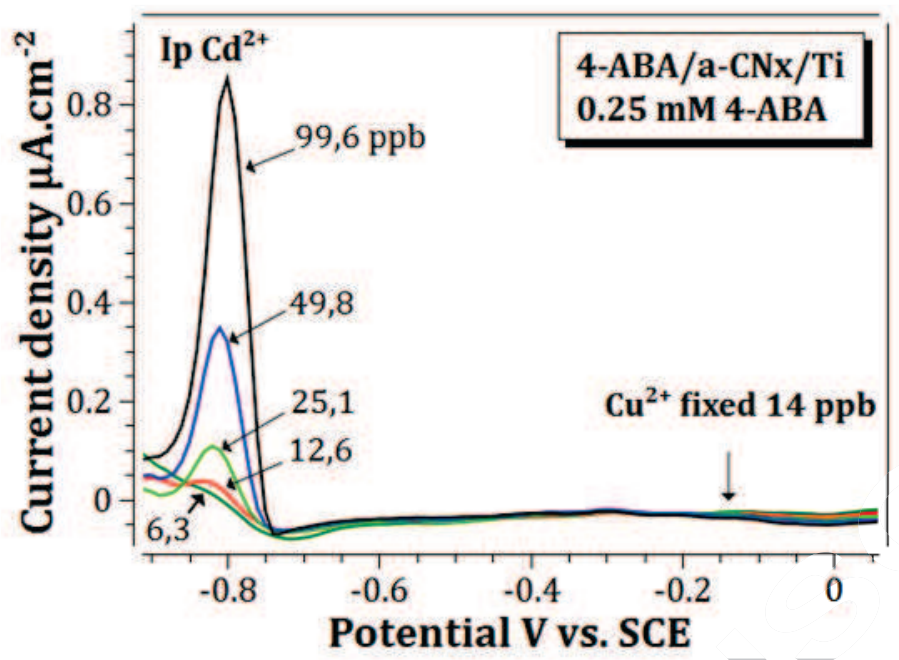

Figure 10 : DPASV voltammograms (adjusted by removing reference curve) for $\mathrm{Cd}^{2+}$ detection with fixed $\mathrm{Cu}^{2+}$ concentration (14 ppb) obtained with a-CNx modified electrode by electrografting from 4ABA diazonium salt $(0.25 \mathrm{mM})$ in acetate buffer $0.1 \mathrm{M} ; \mathrm{pH}=4.9 ; \mathrm{E}_{\text {step }}=10 \mathrm{mV} ; \mathrm{E}_{\text {pulse }}=30 \mathrm{mV} ; \mathrm{E}_{\text {dep }}$ $=-1.1 \mathrm{~V} ; \mathrm{T}_{\text {dep }}=120 \mathrm{~s} ; \mathrm{V}_{\mathrm{b}}=50 \mathrm{mV} \mathrm{s}^{-1}$. 


\section{Highlights}

- a-CNx modified films were obtained by functionalization through diazonium salt.

- The effect of functionalization of a-CNx on $\mathrm{Cd}^{2+}$ and $\mathrm{Cu}^{2+}$ detection is carried out.

- The functionalization leads to a decrease of the electrochemical reactivity.

- The grafting parameters were optimized for $\mathrm{Cd}^{2+}$ and/or $\mathrm{Cu}^{2+}$ detection.

- We observe a sensitive response towards $\mathrm{Cd}^{2+}$ while decreasing the $\mathrm{Cu}^{2+}$ signal. 


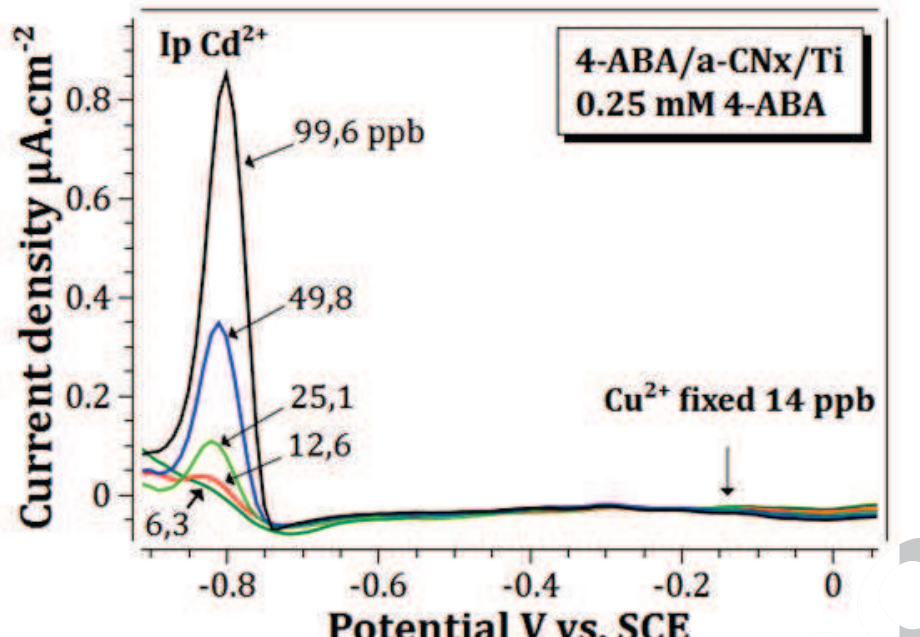

Figure 10 : DPASV voltammograms (adjusted by removing reference curve) for $\mathrm{Cd}^{2+}$ detection with fixed $\mathrm{Cu}^{2+}$ concentration (14 ppb) obtained with a-CNx modified electrode by electrografting from 4ABA diazonium salt $(0.25 \mathrm{mM})$ in acetate buffer $0.1 \mathrm{M} ; \mathrm{pH}=4.9 ; \mathrm{E}_{\text {step }}=10 \mathrm{mV} ; \mathrm{E}_{\text {pulse }}=30 \mathrm{mV} ; \mathrm{E}_{\text {dep }}$ $=-1.1 \mathrm{~V} ; \mathrm{T}_{\mathrm{dep}}=120 \mathrm{~s} ; \mathrm{V}_{\mathrm{b}}=50 \mathrm{mV} \mathrm{s}^{-1}$. 